\title{
An Innovative Method for Iris Positioning in a Prosthetic Eye
}

\author{
Vikram M Belkhode ${ }^{1}$, Sharayu V Nimonkar² ${ }^{2}$ Sudesh C Chaudhary ${ }^{3}$, Anuja Hakkepatil ${ }^{4}$, Pranali Nimonkar ${ }^{5}$, Jyoti Prajapat ${ }^{6}$
}

\begin{abstract}
Aim: An apparatus named "laser pointer apparatus" is proposed for accurate iris positioning in a prosthetic eye.

Background: Loss of an eye leads to significant psychological stress due to functional disability and societal response to the facial disablement. Custom-made eye prosthesis is a good option to rehabilitate such defects. Inaccurately positioned iris in a prosthetic eye results in squint eye appearance leading to poor esthetics and poor psychological impact among such unfortunate patients.

Technique: A new apparatus called a laser pointer apparatus, which is an assembly of an occlusal plane analyzer, web camera, laser pointer, and software, has been introduced for iris positioning in a prosthetic eye.

Conclusion: Iris positioning is one of the key steps in fabricating an eye prosthesis. Laser pointer apparatus is a reliable method for iris positioning in a prosthetic eye.

Clinical significance: Positioning the iris to the ideal symmetrical position is a cardinal step in the fabrication of an ocular prosthesis. This article aims to introduce a "laser pointer apparatus" to orient iris in a prosthetic eye objectively to overcome the subjective errors.

Keywords: Eye prosthesis, Iris positioning, Laser pointer apparatus, Prosthetic eye.

The Journal of Contemporary Dental Practice (2020): 10.5005/jp-journals-10024-2873
\end{abstract}

"One of the most wonderful things in nature is a glance of the eye; it transcends speech; it is the bodily symbol of identity" -Ralph Emerson.

\section{INTRODUCTION}

The unfortunate loss or absence of an eye may be caused by a congenital defect, irreparable trauma, or tumors. Surgical intervention in the form of evisceration, enucleation, or exenteration of an eye often leads to physical and psychological trauma to the patient and affects their quality of life. ${ }^{1-4}$ Therefore, giving an artificial substitute to reestablish the form and functions is obligatory care for such dysfunction. Rehabilitating such patients with a prosthetic eye has, therefore, become the treatment of choice that not only elevates their psychological status but also restores esthetics and comforts them.

Prosthetic eye can be a prefabricated stock eye or a custommade ocular prosthesis. A custom-made ocular prosthesis reproduces the orientation, natural shade, shape, form, and dimensions of the pupil and iris. It provides naturalism and symmetry to the patient's face. Moreover, it provides a precise adaptation of the prosthesis by obtaining the intimate tissue

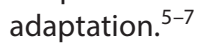

However, fabricating a custom-made prosthetic eye confers many challenges. One of the major challenges being the accurate positioning of an iris. Various techniques have been well documented in the literature for proper positioning of the iris, such as use of pupilometer, anatomical landmarks, ocular locator, profile gauze, visual assessment, tongue blades, rulers, vernier caliper, adobe photoshop, graph grid, spectacles with grid, occlusal plane with gride, etc. ${ }^{8-13}$

To achieve an esthetic outcome, a precise positioning of iris is mandatory. Most of the methods are subjective in nature and may bias the operator to accurately position the iris. To overcome the problems that subsists with conventional subjective methods, objective techniques were preferred.

The present article describes a new approach for accurate positioning of the iris in an eye prosthesis by customizing an objective

\begin{abstract}
1,2Department of Prosthodontics, Sharad Pawar Dental College and Hospital, Datta Meghe Institute of Medical Sciences (Deemed to be University), Sawangi (Meghe), Wardha, Maharashtra, India

${ }^{3}$ Department of Prosthodontics, Dr. Rajesh Ramdasji Kambe Dental College and Hospital, Akola, Maharashtra, India

${ }^{4}$ Department of Conservative Dentistry and Endodontics, DY Patil Dental School, Lohegaon, Pune, Maharashtra, India

${ }^{5}$ Trauma Care Center, Government Medical College, Nagpur, Maharashtra, India

${ }^{6}$ Department of Oral Medicine and Radiology, SGT University, Gurugram, Haryana, India
\end{abstract}

Corresponding Author: Sharayu V Nimonkar, Department of Prosthodontics, Sharad Pawar Dental College and Hospital, Datta Meghe Institute of Medical Sciences (Deemed to be University), Sawangi (Meghe), Wardha, Maharashtra, India, Phone: +91 8830977678, e-mail: snimonkar@gmail.com

How to cite this article: Belkhode VM, Nimonkar SV, Chaudhary SC, et al. An Innovative Method for Iris Positioning in a Prosthetic Eye. J Contemp Dent Pract 2020;21(7):815-818.

Source of support: Nil

Conflict of interest: None

apparatus called a "laser pointer apparatus," i.e., affordable, easy to use, and recommended for clinical usages in small setups.

\section{TEChNIQUe}

A 30-year-old male patient was referred from the Department of Ophthalmology to the Department of Maxillofacial Prosthetics for rehabilitation of a missing eye with a prosthesis. The patient complained of poor appearances due to loss of the left eye. Past history revealed a traumatic injury to the left eye followed by enucleation. On examination, healthy scleral tissue and synchronous movement of the the conjunctiva were present.

A custom-made ocular prosthesis was planned in this patient, and the treatment procedure was explained to him. A written consent was signed from the patient before starting the treatment. 


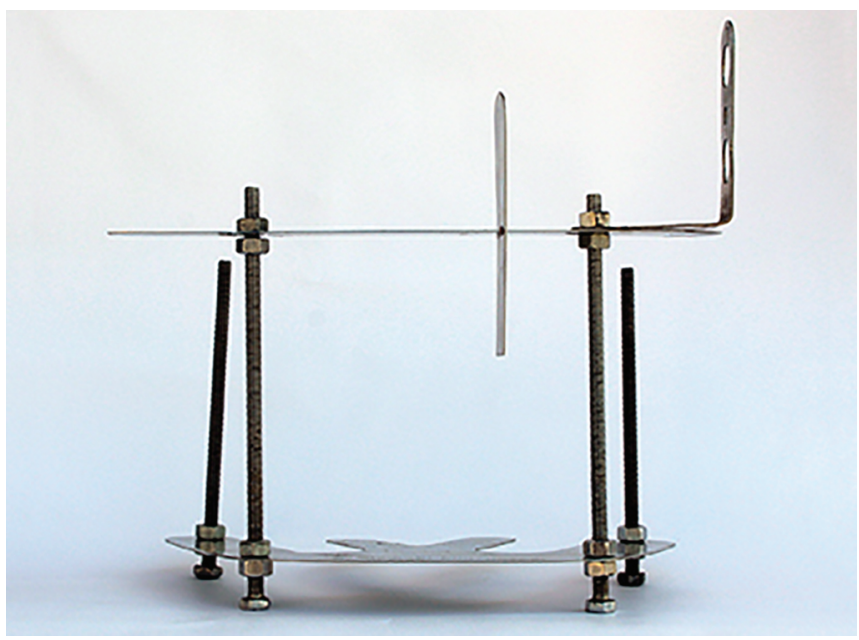

Fig. 1: Laser pointer apparatus (Front view)

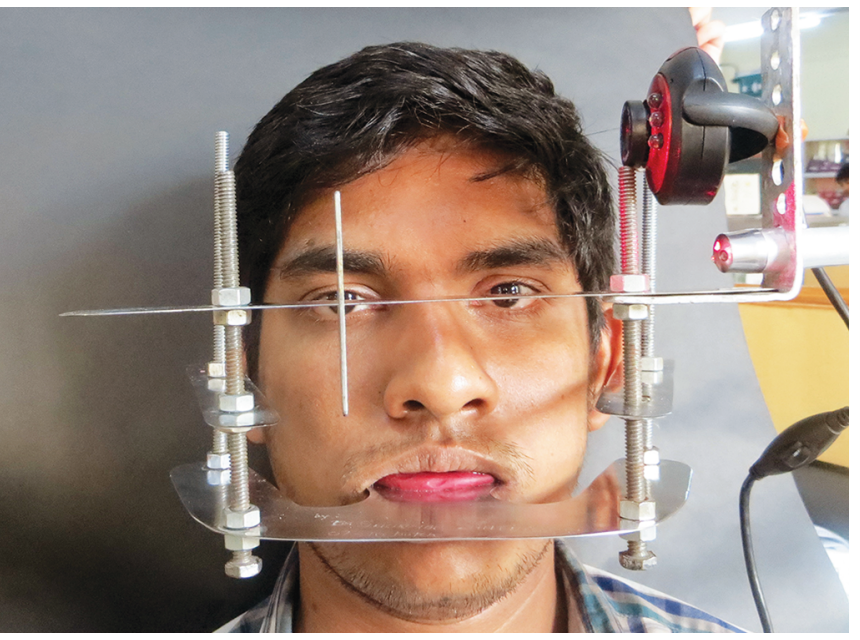

Fig. 3: Laser pointer apparatus in function

An informed consent was also obtained from the ophthalmologist for an ocular prosthesis in this particular patient.

\section{Laser Pointer Apparatus}

Laser pointer apparatus as shown in Figures 1 to 3 comprised of an occlusal plane analyzer, web camera, laser pointer, and software. The occlusal plane analyzer was modified by attaching an "L"-shaped metal frame to the horizontal plate by the side of the normal eye of the patient. This " $\mathrm{L}$ "-shaped metal attachment had holes for the fixation of the laser pointer and the web camera. Another movable vertical plate was attached to the upper (interpupillary) horizontal plate. This movable vertical metal plate along with laser pointer helped to measure the distances of the iris. The web camera was attached to the laptop with the software "laser range finder" (Courtesy: Source code project).

\section{Procedure}

The procedure from a preliminary impression till wax blank fabrication was done conventionally. Then, the laser pointer apparatus was disinfected. The patient was asked to sit in an upright position. The impression compound was put in warm water, kneaded, and placed on bite fork of the occlusal plane analyzer. The patient was asked to bite on the impression compound placed over the

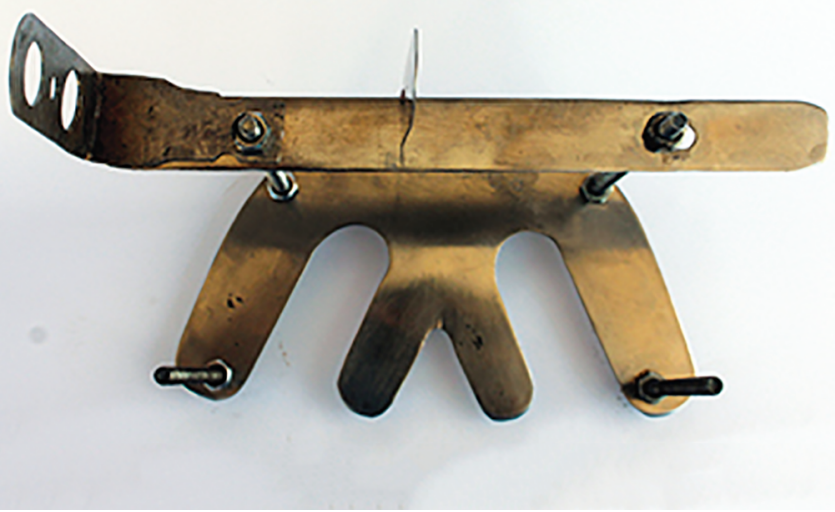

Fig. 2: Laser pointer apparatus (Top view)

bite fork to form the indentation that stabilized and supported the device in position. The horizontal plate was made parallel to the fox plane at the cross-section of the patient's iris, and the plate was stabilized with the bolts.

The "L"-shaped attachment was attached by the side of the normal eye (right eye) of the patient. The movable vertical plate was first positioned at the outer canthus of the normal eye of the patient. Then, the laser pointer was projected on the movable vertical plate. This gave the live distance of the outer canthus of the eye from the laser pointer. The image of the pointer was captured by the web camera that was sent to the computer, and the exact value was calculated by using the following formula.

$$
\begin{aligned}
& D=\left(f^{\prime} \times h\right) / h^{\prime} \\
& h^{\prime} / h=f^{\prime} / D,
\end{aligned}
$$

where $h^{\prime}$ is the height of laser dot (image) from base(image height); $h$ is height of laser beam below the camera (actual height), $f^{\prime}$ is the focus of the camera, the distance of lens to the focal plane, and $D$ is this distance (range) is to be calculated.

The procedure was then followed in the same manner to record the distance of middle canthus and pupil of the iris of the normal eye from the laser pointer by positioning the vertical plate on the middle canthus and center of the pupil, respectively. All the three distances were noted.

After recording the measurements for the normal eye, "L"-shaped attachment was transferred on the affected side (defect eye/left eye) of the patient. The distances recorded earlier for the normal eye was replicated on the affected eye, and accordingly, the iris was positioned in the prosthesis.

After iris positioning, the wax trial prosthesis was verified and it was flasked, dewaxed, and cured in a conventional manner. The prosthesis was then finished, polished, and delivered to the patient. Post-insertion instruction for the care of the prosthesis were explained to the patient and follow-up appointments were scheduled for him.

\section{Discussion}

Fabricating prosthetic eye has been recognized by humans since the antediluvian. Rehabilitating patients with an ocular defect is 
a tough task for a prosthodontist. An ocular prosthesis is either adjusted stock eye shells, also called prefabricated or a custommade prosthesis. Documented literature has shown better results in terms of esthetics and fits with a custom-made prosthesis. ${ }^{14-16}$ To achieve esthetic in a custom-made ocular prosthesis, the precise positioning of the iris is cardinal.

A laser pointer apparatus is a modified occlusal plane analyzer used for a precise iris position in an ocular prosthesis. The occlusal plane analyzer is an instrument that is most commonly used to orient the maxillary plane to the ala-tragus line. Bite fork was used to stabilize the device to reduce the need for assistance during the procedure and a horizontal interpupillary plate was used to attach the movable vertical plate on it at the level of the interpupillary plane.

The use of a laser pointer helped to get the live distance of the iris from the reference point to be measured. Further chances of errors in measurement were eliminated by the use of softwarederived formula to calculate the exact distances of the iris. Apparatus was disinfected with $2 \%$ gluteraldehyde before use per the disinfection protocol. ${ }^{17,18}$

Since it is a modified occlusal plane analyzer, the apparatus is bulky which is the only limitation of this apparatus. The authors are working to make the apparatus compact for patients' comfort.

Guttal et al. utilized a grid template to place the iris accurately. ${ }^{19}$ But this method requires an assistant to hold the graph and is subjective to interobserver error. Pai et al. and Dasgupta et al. in 2010 used an eyewear with a graph grid attached to its glass lens and designed spectacles with transparent gridded acrylic glasses similar to Kestenbaum glasses to orient iris in a prosthetic eye. ${ }^{20,21}$ Chamaria et al. customized an acrylic resin frame with a graph grid assembly attached to a face bow for iris positioning. ${ }^{22}$ Shetty et al. used Hanau Spring bow to orient iris. The technique using Spring bow cannot be used in patients without ear. ${ }^{23}$ Lokendra et al. used a customized scale for iris positioning, but the construction of such a customized scale is not only tedious but also has chances of fabrication errors. ${ }^{24}$

Bhochhibhoya et al. in 2019 used PD ruler to position the iris in eye prosthesis, ${ }^{25}$ but failed to be useful in facial asymmetry cases. Chihargo et al. in 2019 used optical venire IPD ruler, and Lanzara et al. used electronic Venier caliper to orient iris. ${ }^{26,27} \mathrm{Bi}$ et al. used a three-dimensional scanning (CAD-CAM), system and Dasgupta et al. used digital photography for iris positioning. . $^{21,28}$

The advantages of using this laser pointer device over other methods are that it measures the distances accurately unlike other manual or subjective methods, the need for assistances during procedure is eliminated, it is less time consuming and is not technique sensitive, device is portable, it can be customized by the operator and used in multiple patients, can be used in small setups, allows repeated checking of the iris positioning, can be used in patients with facial asymmetry, and can be used in both dentulous and edentulous patients.

\section{SUMMARY}

Symmetry is the essence of esthetic, and an ocular prosthesis is not an exception to it. The correct orientation of iris, to a great extent, contributes to the success of ocular prosthesis. The technique described using a Laser Pointer Device in this article is an accurate, affordable, easy-to-use, and comfortable to the patient and recommended for clinical use in small setups.

\section{ACKnOWLedgments}

The authors wish to acknowledge the help, support, and permission of Hon. Vice Chancellor of DMIMS (DU), the teaching and nonteaching staff of the Department of Prosthodontics, and fellow colleagues for their encouragement and contribution in this study. The study is neither published nor presented anywhere before submitting it to the journal.

\section{References}

1. Perman KI, Baylis HI. Evisceration, enucleation, and exenteration. Otolaryngol Clin North Am 1988;21(1):171-182.

2. Belkhode VM, Nimonkar SV, Aashika A, et al. Prosthodontic rehabilitation of patient with mandibular resection using overlay prosthesis: a case report. J Clin Diagn Res 2019;13(2):ZD10-ZD13.

3. Gondivkar SM, Gadbail AR, Gondivkar RS, et al. Impact of oral potentially malignant disorders on quality of life: a systematic review. Future Oncol 2018;14(10):995-1010. DOI: 10.2217/fon-2017-0577.

4. Nimonkar SV, Belkhode VM, Sathe S, et al. Prosthetic rehabilitation for hemimaxillectomy. J Datta Meghe Inst Med Sci Univ 2019;14:99-102.

5. Cain JR. Custom ocular prosthesis. J Prosthet Dent 1982;48(6): 690-694. DOI: 10.1016/s0022-3913(82)80030-9.

6. Sykes LM. Custom made ocular prostheses: a clinical report. J Prosthet Dent 1996;75(1):1-3. DOI: 10.1016/s0022-3913(96)90409-6.

7. Shivji AR, Bhat S, Shetty P. Prosthodontic management of an ocular defect-a case report. J Indian Prosthodont Soc 2001;1:33-35.

8. Roberts AC. An instrument to achieve pupil alignment in eye prosthesis. J Prosthet Dent 1969;22(4):487-489. DOI: 10.1016/00223913(69)90216-9.

9. Brown KE. Fabrication of orbital prostheses. J Prosthet Dent 1969;22(5):592-607. DOI: 10.1016/0022-3913(69)90234-0.

10. McArthur DR. Aids for positioning prosthetic eyes in orbital prostheses. J Prosthet Dent 1977;37(3):320-326. DOI: 10.1016/00223913(77)90074-9.

11. Supriya $M, G$ Gadiali B. Prosthetic rehabilitation of a patient with an orbital defect using a simplified approach. J Indian Prosthodont Soc 2008;8(2):116-118. DOI: 10.4103/0972-4052.43616.

12. James $\mathrm{H}$, Ellis JR, Foulds. WS. A method of artificial eye manufacture. Br J Ophthalmol 1976;60(2):153-155. DOI: 10.1136/bjo.60.2.153.

13. Benson P. The fitting and fabrication of a custom resin artificial eye. J Prosthet Dent 1977;38(5):532-538. DOI: 10.1016/0022-3913(77) 90029-4.

14. Murphey PI, Schlossberg L. Eye replacement by an acrylic maxillofacial prosthesis. Naval Med Bull 1944;43:1085.

15. Dyer NA. The artificial eye. Aust J Ophthalmol 1980;8(4):325-327. DOI: 10.1111/j.1442-9071.1980.tb00293.x.

16. Doshi PJ, Aruna B. Prosthetic management of patient with ocular defect. J Indian Prosthodont Soc 2005;5(1):37-38. DOI: 10.4103/09724052.16340 .

17. Nimonkar SV, Belkhode VM, Godbole SR, et al. Comparative evaluation of the effect of chemical disinfectants and ultraviolet disinfection on dimensional stability of the polyvinyl siloxane impressions. J Int Soc Prevent Communit Dent 2019;9(2):152-158. DOI: 10.4103/jispcd. JISPCD_406_18.

18. Godbole SR, Dahane TM, Patidar NA, et al. Evaluation of the effect of ultraviolet disinfection on dimensional stability of the polyvinyl silioxane impressions-an in vitro study. J Clin Diagn Res 2014;8:73-77.

19. Guttal SS, Patil NP, Vernekar N, et al. A simple method of positioning the iris disk on a custom-made ocular prosthesis. A clinical report. J Prosthodont 2008;17(3):223-227. DOI: 10.1111/j.1532849X.2007.00272.x.

20. Pai UY, Ansari NA, Gandage DS. A technique to achieve predictable iris positioning and symmetry in ocular and orbital prostheses. J Prosthodont 2011;20(3):244-246. DOI: 10.1111/j.1532849X.2011.00692.x. 
21. Dasgupta D, Das K, Singh R. Rehabilitation of an ocular defect with an intraorbital implant and custom-made prosthesis using digital photography and gridded spectacle. J Indian Prosthodont Soc 2019;19(3):266-271. DOI: 10.4103/jips.jips_226_18.

22. Chamaria A, Aras MA, Chitre V, et al. Iris positioning using a grid attached to a spring bow for a custom ocular prosthesis. J Clin Diagn Res 2017;11(3):ZD1-ZD3. DOI: 10.7860/JCDR/2017/22011.9460.

23. Shetty PP, Chowdhary R, Yadav RK, et al. An iris positioning device and centering approach: a technique. J Prosthet Dent 2018;119(1):175-177. DOI: 10.1016/j.prosdent.2017.01.018.

24. Lokendra G, Aparna IN, Dhanasekar B, et al. Three-dimensional orientation of iris in an ocular prosthesis using a customized scale. J Prosthodont 2014;23(3):252-255. DOI: 10.1111/jopr. 12104.
25. Bhochhibhoya A, Mishra S, Mathema S, et al. Alternative technique of iris orientation in a custom-made ocular prosthesis. J Prosthodont 2019;28(5):601-604. DOI: 10.1111/jopr.12687.

26. Chihargo $S$. CRC1: iris positioning technique by using optical vernier interpupillary distance ruler on the custom ocular prosthesis. Indian Prosthodont Soc 2018;18(Suppl 1):S35. DOI: 10.4103/09724052.244655.

27. Rajat L, Ashish T, Viswambaran M, et al. Fabrication of ocular prosthesis with a digital customization technique - a case report. J Family Med Prim Care 2019;8(3):1239-1242. DOI: 10.4103/jfmpc. jfmpc_133_19.

28. $\mathrm{Bi} Y$, Wu S, Zhao Y, et al. A new method for fabricating orbital prosthesis with a CAD/CAM negative mold. J Prosthet Dent 2013;110(5):424-428. DOI: 10.1016/j.prosdent.2013.05.003. 